\title{
Pausanias, la libertad griega y la historia de la Confederación Aquea helenística: Memoria e identidad griegas en el Imperio romano ${ }^{1}$ \\ Pausanias, Greek Freedom and History \\ of the Hellenistic Achaean Confederacy: \\ Greek Memory and Identity in the Roman Empire
}

\author{
Álvaro M. MORENO LEONI \\ Universidad Nacional Autónoma de México \\ moreno.leoni@gmail.com
}

\begin{abstract}
RESUMEN: El objetivo de este artículo es analizar el concepto de libertad griega en la Periégesis de Pausanias, evaluando la importancia de la historia de la Confederación Aquea helenística que propone este autor durante el siglo II d. C., a fin de entender la definición de su proyecto cultural e ideológico basado en el rescate de la memoria bajo el dominio romano.

ABSTRACT: The aim of this article is to analyze the concept of Greek freedom in the Periegesis of Pausanias we will do so by assessing the importance of the history of the Hellenistic Achaean Confederacy proposed by this writer during the 2 nd century $\mathrm{BC}$ in order to understand the definition of his cultural and ideological project in an attempt to rescue of the memory under Roman dominion.
\end{abstract}

PAlabras Clave: Pausanias, libertad, historia aquea, memoria, panhelenismo.

KEY WORDS: Pausanias, freedom, Achaean history, memory, Panhellenism.

RECIBIDO: 14 de marzo de 2014 - ACEPTADO: 10 de septiembre de 2014.

\section{Introducción}

"El rasgo fundamental del carácter helénico es un fuerte impulso a determinarse por sí mismo, a formarse un juicio personal sobre las cosas circundantes, a ajustar su vida a su propia voluntad". ${ }^{2}$ Con estas palabras comienza Max Pohlenz su estudio clásico sobre la idea griega de libertad, en el cual recorre las líneas generales de la génesis cultural de este concepto desde la época arcaica hasta los orígenes del cristianismo. Su cuarto capítulo está abocado al derrotero histórico de esta idea durante

${ }^{1}$ Agradezco la lectura previa del texto al Prof. Dr. Ricardo Martínez Lacy. Sus observaciones han permitido mejorar sustancialmente el argumento aquí expuesto. Quisiera expresar también mi gratitud para con el Dr. David Konstan, quien tuvo la amabilidad de enviarme una copia de su artículo sobre Pausanias todavía no publicado.

${ }^{2}$ Pohlenz 1956, p. 9. 
la época helenística, pero allí el sentido político del término se diluye en una disquisición sobre la aparición de distintas "perspectivas espirituales" antes de la llegada del cristianismo. En un plano estrictamente político, sin embargo, la lectura realizada por Plutarco, convence a Pohlenz de que la sumisión de Grecia ante Roma había sido el resultado de una verdadera "necesidad histórica", la cual había venido a dar fin a las luchas incesantes entre los griegos y, en consecuencia, a permitirles beneficiarse de la paz general romana. ${ }^{3}$

Los alcances del concepto griego clásico de libertad eran, pese a la opinión de Pohlenz, mucho más amplios. Jacqueline de Romilly ha observado, en ese sentido, que la noción griega de libertad estaba en la raíz de la tendencia general de las póleis griegas hacia el imperialismo, puesto que para éstas la libertad implicaba no sólo la independencia respecto a un poder externo o interno, sino también la posibilidad de ejercer su propio dominio sobre otros, lo que constituía una especie de segundo grado de libertad. ${ }^{4}$

¿Qué podía significar, entonces, la libertad para los griegos del siglo II d. C.? La nueva realidad del dominio romano parecía haberla limitado hasta el punto de hacerla desaparecer, ya que ahora los griegos no sólo estaban imposibilitados de dominar a otros, sino que, además, debían obedecer también todas las órdenes emanadas de las autoridades provinciales designadas por los romanos. Antes de la conquista romana, las póleis habían podido hacer un uso estratégico de sus márgenes de libertad para actuar dentro de una realidad interestatal mediterránea con múltiples actores, preservando así cierto nivel de autonomía, pero esto se volvió imposible a partir del siglo II a. C. Plutarco explica de forma inigualable la nueva condición de los griegos cuando, en sus Consejos Políticos, se dirige a Menémaco de Sardes para recordarle: "Gobiernas a la vez que eres gobernado, pues tu ciudad está sometida a los procónsules, a los procuradores de César". La comparación con un líder ateniense de época clásica y sus reflexiones ("Cuidado, Pericles. Gobiernas a hombres libres, gobiernas a griegos, a ciudadanos atenienses"), no hacía más que volver evidente el punto: las decisiones griegas tenían ahora que contemplar de cerca los dictados de la política romana. ${ }^{5} \mathrm{Ni}$ el pueblo, ni

\footnotetext{
${ }^{3}$ Ib., p. 140.

${ }^{4}$ De Romilly 1947, p. 73.

${ }^{5}$ Plu., Mor., 813 D-E.
} 
los miembros de la élite podían considerarse libres en el nuevo contexto, pero Plutarco (pese a la interpretación de Pohlenz), estaba lejos de aconsejar a sus lectores la pasividad, porque creía que éstos debían ser activos y responsables para evitar forzar a los romanos "a ser sus amos más de lo que deseaban". 6

Mantener un cierto nivel de autonomía, por lo tanto, era lo deseable. Pero ¿qué puede decirse respecto a la libertad? ¿Qué tipo de interés podían llegar a tener los griegos del siglo II d. C., por ejemplo, en el recuerdo de su libertad pasada? Proponemos aquí explorar las ideas de Pausanias al respecto porque consideramos que pueden contribuir a comprender el sentido que la memoria de la Grecia libre tenía para la identidad griega bajo el dominio romano. Al mismo tiempo, nos interesa reconocer qué relación existe entre la idea de libertad y la lectura del pasado griego. En ese sentido, en su obra se advierte una particular preocupación por la historia del período helenístico tardío, momento histórico en el que Grecia había perdido su libertad tras el fin de la guerra aquea. ¿Por qué esta preocupación? De acuerdo con la propuesta de Joël Candau sobre "memoria" e "identidad", se buscará aquí entender de qué modo quien recuerda el pasado, puede domesticarlo, apropiárselo, incorporarlo y, al mismo tiempo, imprimirle su sello como un "etiquetaje memorialista que cumple la función de significante de la identidad". ${ }^{7}$ Pausanias no podía narrar todas las cosas de Grecia y, por ello, optó por registrar sólo lo

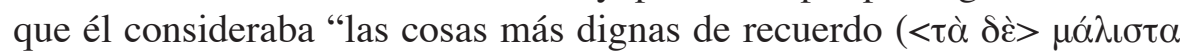

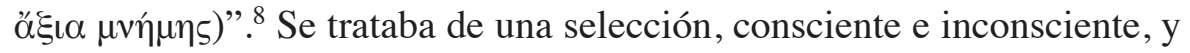
como tal no era neutra. ${ }^{9}$

\section{Pausanias y su obra: estado de la cuestión}

¿Quién era Pausanias y qué clase de obra escribió? Los diez libros de la Periégesis fueron escritos entre 155 y 175 d. C. por un enigmático autor microasiático originario de la zona de Magnesia del Sipilo, en

\footnotetext{
${ }^{6}$ Plu., Mor., 824 C.

${ }^{7}$ Candau 2008, p. 70.

${ }^{8}$ Paus., III, 11,1 .

${ }^{9}$ Se ha utilizado la edición de Domenico Musti, Gianfranco Maddoli y Mauro Moggi (1982-2012) de la Fondazione Lorenzo Valla. La traducción es de María Cruz Herrero Ingelmo (1993), con ligeras modificaciones.
} 
Lidia. ${ }^{10}$ Viajó por gran parte de Grecia continental y propuso a sus lectores un recorrido por los monumentos antiguos que eran aún visibles en esa tierra, pero también por su historia y su cultura. Su carácter de griego no-continental le permitió tomar cierta distancia frente al territorio recorrido y descrito, ofreciendo a los lectores una selección bastante personal del espacio, que no era la totalidad de "Grecia", sino un espacio casi equivalente al de la provincia de Acaya. Grandes áreas, sin embargo, quedaban fuera de su selección: Las islas - excepto Egina-, Etolia, Acarnania y Tesalia. Tampoco Epiro o Macedonia eran mencionados. ${ }^{11}$

Su objetivo principal era describir los monumentos, lugares y rutas dignas de ver ( $\theta \varepsilon \omega \varrho \eta ́ \mu \alpha \tau \alpha)$, pero lo más importante era convertirlos en objetos significativos para sus lectores, por lo que insertó pródigamente digresiones ( $\lambda$ ó $\gamma \mathrm{ol}$ ) históricas, míticas y religiosas relacionadas con los mismos. ${ }^{12}$ De acuerdo con la tradición geográfica griega, buscó de ese modo dotar de sentido los lugares para beneficio del público, ${ }^{13} \mathrm{y}$, de hecho, este formato lo convirtió en un autor muy popular entre los primeros europeos que durante los siglos XVIII y XIX llegaron como turistas a Grecia. Pausanias y sus lectores modernos parecían tener objetivos similares, pues todos buscaban conocer el pasado de Grecia a través de sus restos materiales todavía visibles. ${ }^{14}$

Podemos señalar que nuestra propuesta presente parte de la observación de tres avances notables experimentados durante las últimas tres décadas en el estudio de la Periégesis, que tienen que ver con la concepción general de la obra, la relación con el contexto cultural e ideológico de la Segunda Sofística y las operaciones de memoria propuestas en el texto.

${ }^{10}$ Habicht 1985, pp. 10-15. Su origen en Magnesia del Sipilo lo atestigua el mismo autor, Paus., V, 13, 7.

${ }^{11}$ El recorte del territorio griego: Hutton 2005, pp. 55-68. Casi identidad con el territorio de la provincia romana: Alcock 1993. Existe, sin embargo, una referencia a un libro XI sobre Eubea (Steph. Byz., s.v. Tamyna), que se considera generalmente un error de un copista.

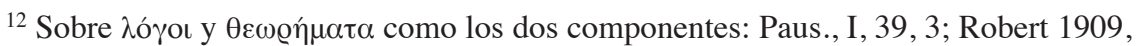
pp. 3-7, 8-38, 39-68.

${ }^{13}$ Musti 1984.

${ }^{14}$ El primero de ellos fue Edward Dodwell (1767-1832), pero también William Gell (1777-1836), E. D. Clarke (1769-1822) y William Martin Leake (1777-1860), este último fue el famoso autor de una topografía de la antigua Atenas, Dyson 2008, pp. 96-97. 
Concepción general de la obra

El género es una cuestión particularmente problemática y discutida. Aunque existía en la antigüedad un tipo de escritura "periegética", con descripción de ciudades o regiones, no se ha conservado ningún otro ejemplo de la misma. Lo poco que se conoce es que su alcance geográfico era más bien modesto y, en ningún caso, llegaba a adoptar la magnitud del recorrido propuesto por Pausanias. De hecho, Giorgio Pasquali, en su clásico artículo, censuraba al escritor griego por haber excedido unos supuestos límites del género periegético. ${ }^{15} \mathrm{El}$ problema es que no existen pruebas de la existencia de tal "género", con reglas explícitas e implícitas, y la obra de Pausanias, con su énfasis en el recorrido, descripción y explicación detallada, parece ser única dentro de la tradición literaria griega. ${ }^{16}$

Jás Elsner, por ejemplo, observó que en esta obra se fundieron elementos del "arte de la memoria" y de la "periégesis", junto con la tradición de los "relatos de viaje" y los "catálogos de viaje imperiales". ${ }^{17} \mathrm{Sin}$ embargo, tampoco podría considerarse a Pausanias strictu sensu un geógrafo, puesto que su concepción espacial tiene claros límites, que se reconocen en su provisión a los lectores de imprecisos diagramas lineales de rutas que, en realidad, no servían como una verdadera guía práctica para viajar a través de Grecia. ${ }^{18} \mathrm{Al}$ respecto, David Konstan ha sugerido que quizás Pausanias no estuviera escribiendo para "peregrinos" o para "turistas", que quisieran visitar a Grecia llevando consigo esa obra como guía. Por el contrario, podría haberlo hecho para que esta fuera leída por los miembros de la élite en sus villas, a quienes les habría suministrado sólo claves mnemónicas para poder asociar los monumentos con historias y personajes griegos excepcionales. ${ }^{19}$ Esta reciente interpretación resulta estimulante porque permite reconocer la importancia de las historias asociadas, el componente narrativo, por sobre los monumentos y lugares, o componente descriptivo de la obra.

\footnotetext{
15 Pasquali 1913.

${ }^{16}$ Hutton 2005, p. 250; Pretzler 2007, p. ix.

${ }^{17}$ Elsner 2001, p. 20.

${ }^{18}$ Pretzler 2007, p. 69.

${ }^{19}$ Konstan 2014, p. 258.
} 
La naturaleza fuertemente "histórica" de la descripción pausaniana es lo que, en las últimas décadas, ha llamado particularmente la atención de los especialistas. Una hipótesis que goza de cierto prestigio actualmente es que se trataría de una obra con un fuerte matiz historiográfico, aunque no sería propiamente una "historia". De acuerdo con Domenico Musti, la Periégesis debería ser entendida como una "lectura histórica del paisaje". ${ }^{20}$ François Chamoux, por su parte, ha planteado que debería entendérsela como "una obra de historia sobre una base topográfica". ${ }^{21}$ El reconocimiento de este peso de lo narrativo-histórico por sobre lo descriptivogeográfico no es ciertamente nuevo, puesto que ya, a principios del siglo XX, Adolf Trendelenburg había observado que las digresiones mitohistóri-

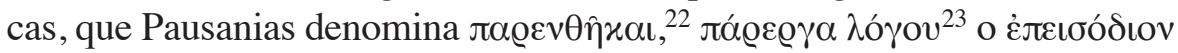
$\tau \hat{\omega} \lambda{ }^{\prime} \gamma \omega{ }_{1}{ }^{24}$ representaban prácticamente la mitad del texto. ${ }^{25}$ La presencia de la historia en su obra, por lo tanto, no debería concebirse como la de un mero adorno para acompañar las descripciones de su recorrido.

Las consecuencias de esta hipótesis son profundas, pues la misma ha llevado a dejar de lado equiparaciones con las guías turísticas contemporáneas, como la Baedeker o la Blue Guide, ya que a esta comparación subyacía una concepción de la Periégesis como mera compilación "objetiva" de anécdotas curiosas para los lectores antiguos y útiles para historiadores, arqueólogos y filólogos modernos dispuestos a diseccionar el texto en busca de datos. Según la feliz expresión de William Hutton, para estos especialistas, Pausanias no era más que un "dependable dullard" o un zopenco fiable carente de interpretación propia. ${ }^{26}$ Unido a esto último, la comprensión de la obra como una mera guía útil para los miembros de la élite durante su Grand tour por Grecia continental tampoco se sostendría, puesto que el texto parece más bien "estar pensado para informar a aquellos que se quedaban en casa sobre cómo era la Grecia contemporánea, sobre qué podía hallarse allí y dónde podía hallarse, así como también proporcionar una visión de conjunto de Grecia, del

\footnotetext{
${ }^{20}$ Musti 1994, p. 14.

${ }^{21}$ Chamoux 1974, p. 83. Cf. Hutton 2005, p. 117.

22 Paus., I, 8, 1.

${ }^{23} \mathrm{Ib} ., \mathrm{I}, 9,4$.

${ }^{24}$ Ib., VIII, 8, 1.

25 Trendelenburg 1914, pp. 15 ss.

${ }^{26}$ Hutton 2005, p. 4, passim.
} 
pasado y del presente". ${ }^{27}$ A pesar de la firme creencia de los cultores de la Quellenforschung, la obra no era ni un producto objetivo, ni una reproducción mecánica de fuentes más antiguas, sino que Pausanias, como autor, tenía "opiniones, sentimientos y preferencias que están en su obra más a menudo de forma implícita que explícita". ${ }^{28}$

El contexto cultural e ideológico de la Segunda Sofística

La Periégesis tampoco puede verse como un producto desvinculado del contexto cultural o político-ideológico de la Segunda Sofística, como la ha denominado Simon Swain..$^{29}$ La élite griega emprendió durante esa época, al menos desde mediados del siglo i hasta el III d. C., un vasto proyecto de examen de su propia cultura. ${ }^{30}$ Para los intelectuales griegos del periodo no todo el pasado merecía la misma atención y, en consecuencia, su atención se centró generalmente en determinados episodios de la historia griega clásica y posclásica, en particular, en las guerras Médicas, la invasión de Filipo II y la conquista del Imperio persa por Alejandro Magno, puesto que permitían poner el acento en las glorias del pasado en el marco de la realidad del dominio romano. ${ }^{31} \mathrm{Al}$ mismo tiempo, permitían establecer una distancia con el momento histórico de la conquista de Grecia, evitando embarazosas reflexiones sobre los pormenores de la sujeción a Roma. La historia, devenida en memoria histórica, podía adoptar un sentido de desafío. En ese sentido, uno de los consejos de Plutarco a su amigo Menémaco, quien aspiraba a convertirse en político, era el de apartarse de temas como "Maratón, Eurimedonte y Platea", tan proclives a agitar las pasiones de la masa. ${ }^{32}$

Una diferencia clave de Pausanias respecto a la Segunda Sofística, sin embargo, es su actitud frente al pasado, puesto que aunque para el periegeta los temas mencionados de la historia griega clásica eran im-

${ }^{27}$ Arafat 2004, p. 36. De todos modos, el centro neurálgico parece ser el Peloponeso, puesto que, según Yves Lafond (1994, pp. 170-171), siete décimas partes del contenido de la Periégesis están relacionadas con esta península.

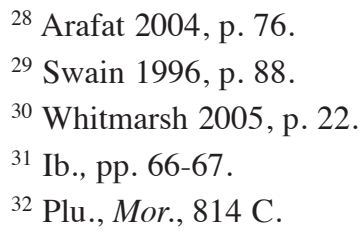


portantes, también lo eran los acontecimientos helenísticos. ${ }^{33}$ De hecho, es actualmente considerado como una fuente intermedia inestimable para conocer aspectos de la historiografía helenística, sólo conocida en muchos casos a través de testimonios y fragmentos. ${ }^{34}$ La historia para él, además, no era sólo una colección de tópicos históricos fosilizados, sino que la reinterpretación de la misma era una parte central de su propuesta. ${ }^{35}$ En algunos casos, como en el del libro I (Ática y Megáride), el IV (Mesenia), el VII (Acaya) o el VIII (Arcadia), el predominio de

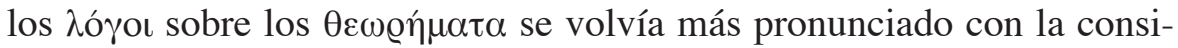
guiente importancia de la aproximación histórica.

Las operaciones de memoria y la historia de la Confederación Aquea helenística

La historia helenística es importante para Pausanias porque es el momento en el cual los griegos perdieron definitivamente su libertad y se estableció la dominación romana. El autor aborda esto in extenso en su relato de la guerra aquea, que revela el carácter más comprometido de Pausanias frente al pasado, al narrar justamente un hecho tan polémico y cargado de consecuencias para los griegos posteriores. Allí, el motivo de la libertad griega, como una experiencia colectiva vivida desde el pasado, se volvía una cuestión cardinal al abordarse uno de los últimos episodios históricos de la Grecia libre con el ascenso y la caída de la Confederación Aquea. Se ensaya allí una selección histórica y una domesticación del pasado en las que la experiencia de los aqueos se eleva a un nivel panhelénico, estableciéndose una identidad entre éstos y los griegos en un sentido general. James Porter ha propuesto algo importante, desde este punto de vista, para entender el sentido de esta operación cuando señaló que la Periégesis puede ser interpretada como un proyecto panhelénico contra la pérdida de memoria, puesto que, al recordar la libertad, según Pausanias, los griegos no sólo se volvían capaces de conmemorarla, sino también de preservar la posibilidad hipotética de volver a ejercerla algún día. ${ }^{36}$

33 Otros autores se limitan al periodo clásico y preclásico: Bowie 1974, pp. 178-179. Aunque había excepciones como algunas de las Vidas de Plutarco, la Historia romana de Apiano y la Historia de los sucesores de Arriano.

${ }^{34}$ Bearzot 1992.

35 Ebeling 1914, p. 138.

${ }^{36}$ Porter 2001, p. 75. 
Su narración del proceso de ascenso de la Confederación Aquea helenística y su posterior guerra contra los romanos, en nuestra opinión, se inserta dentro de este proyecto cultural e intelectual. La mayor parte de las referencias históricas a esta experiencia política se concentran entre los libros VII y VIII. ${ }^{37}$ Como señala Musti, en ambos libros se observa una descompensación entre narración y descripción, es decir, entre $\lambda o ́ \gamma o l$ y $\theta \varepsilon \omega \varrho \eta ́ \mu \alpha \tau \alpha$, que vuelve a estos libros más históricos que paisajísti$\cos .^{38} \mathrm{El}$ motivo de este predominio narrativo podría interpretarse como una reacción ante la escasez de monumentos importantes para describir en ambas regiones, pero parece más probable que eso ocurría porque en dichos libros el tratamiento de tales acontecimientos históricos resultaba importante al autor para su proyecto cultural, sobre todo en lo concerniente a la cuestión del fin de la libertad griega. Nos adherimos aquí, por lo tanto, a la postura de Susan Alcock respecto de la naturaleza del libro IV sobre Mesenia y el predominio en él de la narrativa de las guerras entre mesenios y espartanos, que ocupa al menos tres cuartos del mismo, como un recordatorio de la lucha por la libertad de un pueblo frente a la opresión. ${ }^{39}$ De otro modo, no podría entenderse que se dedicaran 156 parágrafos de un total de 286 del libro VII sobre Acaya, a la historia aquea hasta la destrucción de Corinto. ${ }^{40}$

Hechas estas consideraciones, nos proponemos a continuación reconocer y problematizar dos cuestiones respecto a la historia de la Confederación Aquea, tal como se desprende de la relectura realizada por Pausanias en época imperial romana:

a) Entender cuál era la perspectiva de Pausanias sobre el problema de la libertad griega y cómo la abordaba, pues esto nos permitirá tener una aproximación desde un ángulo distinto al problema de la libertad para los griegos del siglo II d. C.

b) Indagar acerca de cuál era el papel atribuido por el periegeta a los líderes durante la guerra aquea, intentando reconstruir cuáles eran sus modelos de comportamiento de cara a la defensa de la libertad en otros espacios históricos y narrativos de su obra, lo que nos permitirá entender aspectos de la dimensión moral de su juicio histórico así como tam-

\footnotetext{
${ }^{37}$ Cf. Paus., VII, 7-16; VIII, 6, 1-3; 8, 6-12; 27, 1-17; 30, 8-10; 49-52.

${ }^{38}$ Musti 1994, p. 18.

${ }^{39}$ Alcock 2001, p. 145.

40 Thornton 2005, p. 199.
} 
bién de su perspectiva sobre las consecuencias últimas de la dominación romana.

Ambas cuestiones pueden, posiblemente, permitir aportar aquí algunas reflexiones acerca de la postura histórico-cultural de Pausanias entre el mundo griego y el mundo romano.

\section{El tópico de la libertad griega}

Tras haber narrado la historia de la Confederación Aquea en el libro VII y resumido el final de su resistencia con la destrucción de Corinto por L. Mumio (146 a. C.), Pausanias menciona a continuación que, un tiempo después, el emperador Nerón había decidido dejar totalmente libre a Grecia. ${ }^{41}$ Esta medida resultó de todos modos efímera, pues, continúa Pausanias su relato, "después de Nerón, se vieron envueltos en una guerra civil y, de nuevo, Vespasiano ordenó que pagaran tributo y que obedecieran a un gobernador, diciendo que el pueblo griego había perdido el hábito de la libertad". ${ }^{42}$ Después del gesto asombroso de Nerón en el año 67 d. C., ${ }^{43}$ tan importante como para no omitirlo en un relato bastante sintético, aunque Pausanias sí había actuado así en el caso de la famosa proclama en el istmo de T. Quincio Flaminino (196 a. C.), la pérdida de la libertad de los griegos no tenía vuelta atrás. ${ }^{44}$ Uno podría sospechar, sin embargo, que la decisión de Vespasiano no era bien recibida por el periegeta, lo que se vuelve por demás evidente si se reflexiona sobre la importancia que en su obra se atribuye al tópico de la libertad griega como una suerte de impugnación de la opinión de este emperador romano al respecto.

La reacción de Pausanias no se compara, de todos modos, con la que supuestamente habría tenido Apolonio de Tiana frente a esta deci-

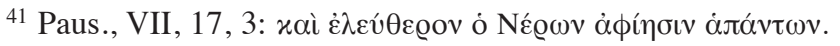

42 Ib., VII, 17, 4. Cf. Habicht 1985, p. 123.

${ }^{43}$ La ambivalente imagen de Nerón en el mundo griego puede verse en Forte 1972, pp. 231-238, 256-257; Bowersock 1987, pp. 308-311.

${ }^{44}$ Se puede hablar de omisión, de acuerdo con Swain (1996, pp. 336-337), porque, primero, era un hecho conocido por todos los griegos; segundo, porque el mismo Pausanias en X, 34, 4 señala que Flaminino había sido enviado a Grecia para liberarla. Cf. Palm 1959, p. 65, quien sigue este pasaje para hablar de que Pausanias ve a los romanos esencialmente como "liberadores". 
sión de Vespasiano, pues, según Filóstrato, ${ }^{45}$ éste habría roto de inmediato relaciones con el emperador a raíz de esto y lo habría acusado, además, de haber excedido a Jerjes con tal decisión. Según Pausanias, este emperador romano acusaba a los griegos de "haber desaprendido" ( $\dot{\pi} \mu \mu \varepsilon \mu \alpha \theta \eta x \varepsilon ́ v \alpha \iota)$ el uso de la libertad. ¿Hasta qué punto Pausanias buscaba recordar a los griegos, por lo tanto, en qué consistía la libertad para demostrar que Vespasiano estaba equivocado? Por lo tanto, así el recurso al pasado no sería un ejercicio trivial. Si los griegos no eran libres en el presente, era el resultado tangible de un largo proceso histórico en el cual la intervención romana era sólo el suceso más reciente y más dramático, pero, de ningún modo, definitivo de la historia griega, que no podía considerarse acabada con la conquista romana.

Un pasaje importante para entender el marco intelectual de su construcción se encuentra en el libro I, sobre Ática, donde el periegeta se topa en su recorrido con una estatua del famoso orador Isócrates y llama la atención de sus lectores sobre tres aspectos memorables acerca de este hombre. El primero era que había educado discípulos hasta el día de su muerte, a los noventa años; el segundo, que había podido mantenerse alejado de la política activa y, el tercero, "el más digno de un hombre libre ( $\dot{\varepsilon} \lambda \varepsilon v \theta \varepsilon \varrho \omega ́ \tau \alpha \tau o v) "$, había sido que, "adolorido por la noticia de la derrota de Queronea, se dejó morir voluntariamente" tras conocerla. ${ }^{46}$ Existen otras tradiciones sobre su muerte, ${ }^{47}$ pero no importa aquí tanto la veracidad, sino lo que sus afirmaciones revelan sobre su perspectiva político-cultural: Una admiración por el saber típica de la "élite culta" o $\pi \varepsilon \pi \alpha \iota \delta \varepsilon v \mu \varepsilon ́ v o l$; luego, una tendencia moderada en política y, por fin, una centralidad atribuida por él al tema de la libertad griega.

La batalla de Queronea (338 a. C.) representaba en su obra un hito importante en el camino que conducía a la pérdida de la libertad para los griegos, opuesto a lo que había ocurrido en el siglo v a. C. con las Guerras Médicas cuando los griegos sí habían sido capaces, por el contrario, de conjurar la amenaza que se cernía sobre su libertad y de rechazar a los persas. Para Pausanias: "El desastre de Queronea estuvo en el origen de las desventuras de todos los griegos, y sobre todo hizo esclavos a los

\footnotetext{
${ }^{45}$ Philostr., VA, V, 41.

${ }^{46}$ Paus., I, 18, 8.

${ }^{47}$ Frazer 1913, pp. 183 s.
} 
indiferentes y a cuantos se alinearon de parte de los macedonios" ${ }^{48}$ De ese modo, una acción específicamente tebana y ateniense era elevada al nivel de una lucha panhelénica por la libertad, lo que permite establecer un claro contraste respecto a Polibio y su evaluación de la participación parcial de los griegos en dicha batalla.

Para el periegeta muchos griegos que ante esta batalla habían decidido mantenerse indiferentes o que, incluso, habían apoyado a Filipo II, se habían vuelto con ello "esclavos", lo que contrasta con lo señalado por Polibio, quien criticaba a Demóstenes por haber acusado a varios de los líderes griegos de traición a la causa griega por no haber apoyado a Atenas en aquella ocasión. ${ }^{49}$ Polibio consideraba, por su parte, que dicha acusación no tenía en cuenta la realidad particular de estos estados griegos, puesto que con el ascenso de Filipo muchas póleis habían podido "respirar y cobrar una idea de libertad". ${ }^{50}$ La óptica de Polibio estaba centrada en el Peloponeso, y en el papel opresor de Esparta (algo no desconocido para Pausanias), y justificaba, en consecuencia, la acción de estos políticos peloponesios desde un punto de vista eminentemente pragmático. ${ }^{51}$

Pausanias no veía el asunto desde la misma óptica, sino que prefería definir a Queronea como una gesta colectiva griega en defensa de la libertad. En su visión del pasado no valían los matices regionales, puesto que para él o se estaba del lado de la libertad griega o del de la esclavitud macedonia. Una práctica recurrente en la Periégesis era señalar, en concordancia con esta visión panhelénica maniquea, el pedigrí de una comunidad por su participación o no en las grandes gestas panhelénicas (Troya, Maratón, Termópilas, Platea, Queronea, Lamia y Delfos). Sólo a modo de ejemplo, puede mencionarse su observación sobre el contingente arcadio aniquilado cerca de Queronea por Q. Cecilio Metelo durante la Guerra Aquea: "Cuando regresaban al Peloponeso, aparecieron de pronto Metelo y los romanos en Queronea. Allí alcanzó el castigo de los dioses griegos a los arcadios que entonces, en el mismo lugar en el que abandonaron a los griegos que luchaban frente a Filipo y los macedonios, murieron a manos de los romanos". ${ }^{52}$ No se aceptan, por lo tanto,

\footnotetext{
${ }^{48}$ Paus., I, 25, 3.

${ }^{49}$ Plb., XVIII, 13-15.

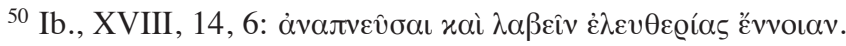

${ }^{51}$ Ib., XVIII, 14, 10-11.

${ }^{52}$ Paus., VII, 15, 6.
} 
las excusas por no haber participado en esa gesta colectiva y haber, en cambio, abrazado la causa macedonia. ${ }^{53} \mathrm{Su}$ interpretación panhelénica se observa también cuando en su recorrido por Élide, donde halló el Filipeo, dice que "fue construido por Filipo después de que la Hélade sucumbiera en Queronea" ${ }^{54} \mathrm{Ni}$ Atenas, ni Tebas, sino toda la Hélade había sido derrotada en Queronea, aunque no todos los griegos participaron en la batalla, e incluso muchos de ellos vieron con buenos ojos su resultado.

El panhelenismo de Pausanias, sin embargo, no era inocente. Su idea de la libertad griega no estaba pensada sólo como la defensa frente a poderes externos, sino que tenía en cuenta también la no sujeción de griegos por griegos. Esto, sin duda, sería una novedad en el lenguaje político. Incluso, el periegeta está perfectamente consciente de los usos propagandísticos de la consigna de libertad en el mundo griego ${ }^{55}$ Por ejemplo, cuando el rey espartano Agis I envió heraldos a Elis exigiendo que se diera la libertad a los lepreatas y a los demás súbditos, y los elitanos le respondieron que lo harían cuando los espartanos hubieran liberado primero a los periecos ${ }^{56}$ Del mismo modo, recoge la historia de la paz de Antálcidas (387 a. C.), cuando Agesilao habría preguntado si los tebanos permitirían jurar a cada uno como representantes de las distintas póleis de la Liga Beocia en nombre de sus respectivas ciudades, a lo que Epaminondas le habría respondido: "Espartanos, no antes de que veamos que vuestros periecos juran ciudad por ciudad". ${ }^{57}$

Al respecto, en VIII, 52 se encuentra una valiosa discusión sobre los benefactores comunes de la Hélade en la que se reconoce que la liberación de los griegos de manos de otros griegos constituía el mayor beneficio. Esta discusión se inserta a propósito de la muerte de Filopemén, líder aqueo y, según el periegeta, último "benefactor común de la Hélade" ${ }^{58}$ Entre los otros benefactores, Pausanias cuenta a Milcíades, Temístocles, Leónidas, Jantipo, Leotíquides, Cimón, Conón, Epami-

${ }^{53}$ Cf. Paus., VIII, 6, 2; 7, 4; 27, 10. El hecho de que Pausanias considera la retribución divina como una creíble explicación para el desarrollo histórico se observa en varios casos, como en Pretzler 2007, p. 89.

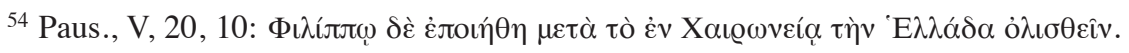

55 Sobre la consigna de libertad en Grecia desde el siglo v a. C., véase Dmitriev 2011.

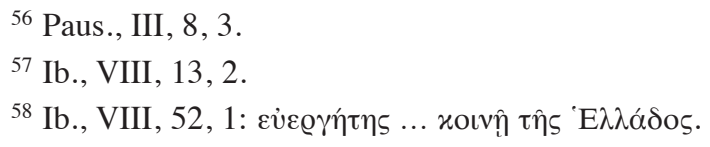


nondas, Leóstenes y Arato. Los criterios de exclusión de esta lista son bastante significativos. Arístides es apartado, por ejemplo, por imponer tributos a los griegos de las islas, atentando contra su libertad. ${ }^{59}$ En otro pasaje, se juzga del mismo modo a Lisandro, por crear las decadarquías y establecer harmostas en las ciudades griegas. ${ }^{60} \mathrm{La}$ inscripción en honor de Filopemén, que Pausanias halló en Tegea, por su parte, lo elogiaba en estos términos: "Son conocidas en toda la Hélade el valor y la fama de este hombre [...] autor de la libertad irreprochable". ${ }^{61}$

Plutarco menciona ya que un romano había definido a este héroe aqueo como el último de los griegos ${ }^{62}$ Esta inscripción honorífica por la cual se homenajeaba a Filopemén por su victoria sobre un "tirano" espartano, posiblemente Macánidas, ${ }^{63}$ en 207 a. C., actuaba como un sello y confirmación de lo expuesto en la breve biografía provista inmediatamente antes, en la cual se habían exaltado la orientación panhelénica y antitiránica de su política, así como su defensa de la autonomía griega ${ }^{64}$ Según Maria Pretzler, Pausanias pudo haber retrasado la introducción de la biografía de Filopemén hasta el momento narrativo de su visita a Tegea para justificar la cita de este epigrama inscrito en la base de una estatua, que debe haberle sido muy difícil de localizar. ${ }^{65}$ Parece más probable, por el contrario, que el epigrama fuera significativo en sí, porque se adaptaba perfectamente a su marco ideológico, y que la inclusión de la biografía fuera adecuada en ese contexto narrativo específico.

Mauro Moggi y Massimo Ossana señalan que esta lectura de las gestas del líder aqueo es muy similar a la realizada por Plutarco en su Vida de Filopemén, pero que esta coincidencia no presupone una lectura directa de la obra del biógrafo, sino posiblemente el acceso de ambos autores a

\footnotetext{
${ }^{59} \mathrm{Ib} ., \mathrm{VIII}, 52,2$.

${ }^{60} \mathrm{Ib} ., \mathrm{IX}, 32,9$.

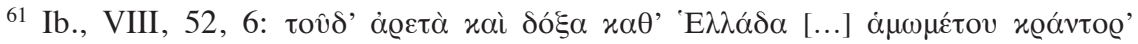
$\dot{\varepsilon} \lambda \varepsilon v \theta \varepsilon \varrho i ́ \alpha s$.

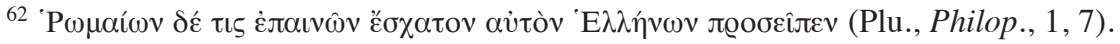

${ }^{63}$ Plb., XI, 18, 7-8.

${ }^{64}$ Bearzot 1995, pp. 707-709. Es poco probable que Macánidas fuera tirano, más bien regente de Pélope, el hijo de Licurgo. Así, Liv., XXVII, 29, 9, tyrannus Lacedaemoniorum, aunque Pélope estaba vivo (cf. Diod., XXVII, 1); Errington 1969, p. 55 , n. 1 .
}

${ }^{65}$ Pretzler 2007, p. 80. 
una misma tradición histórica. ${ }^{66}$ En ese sentido, un pasaje análogo sería VIII, 50, 3, donde Pausanias recuerda una anécdota ocurrida durante la segunda estrategia de Filopemén (205 a. C.), ${ }^{67}$ cuando éste asistió a los Juegos Nemeos y, habiendo entrado al teatro, Pílades comenzó a cantar los versos de los Persas de Timoteo: "Quien procuró el adorno grande y glorioso de la libertad a la Hélade". ${ }^{68}$ Todos los presentes habrían volteado hacia Filopemén expresando así que lo consideraban destinatario de esos versos. A esto añade, además, que sabía que algo similar le había ocurrido a Temístocles en los Juegos Olímpicos. Lo cierto es que Plutarco recogió la misma anécdota (Phil., 11,2). Es muy probable que ambos autores recurrieran al perdido encomio que Polibio escribió sobre su maestro, Filopemén; pero se trata de algo sólo hipotético. ${ }^{69}$

La adhesión de Pausanias al ideal de una defensa de la libertad panhelénica frente a la amenaza del dominio espartano y, por consiguiente, la atribución a Filopemén de esta política, equiparable dentro de sus coordenadas ideológicas a la liberación de Grecia de la amenaza bárbara persa, explica mejor la elección del periegeta. Es claro que Pausanias no tiene una visión positiva de los espartanos. En ese sentido, un pasaje particularmente significativo es aquel en el que, luego de la derrota final de los mesenios a manos de los espartanos y la pérdida de su territorio y libertad, Gorgo y Manticlo suplican al tirano de Regio, Anaxilao, que no los obligue a esclavizar a los habitantes de Zancle después de haber sufrido un trato impío semejante de parte de sus parientes espartanos. ${ }^{70}$ Textualmente, los mesenios dicen que "no les obligase a hacer lo mismo contra hombres griegos". Parece explícita la idea de que los espartanos habrían obrado mal al esclavizar a otros griegos, y el libro IV sobre Mesenia, con su preponderancia de la narrativa histórica, estaba allí para conmemorar no sólo las gestas realizadas por los mesenios en defensa de su libertad, sino también para condenar la actitud de los espartanos.

Volviendo a Filopemén, y al interés de Pausanias por él, es muy probable que detrás de su leyenda panhelénica se esconda el retrato positivo

${ }^{66}$ Moggi y Ossana 2003, p. 523. Errington 1969, pp. 238-240, seguido por Swain 1996, p. 335; por el contrario, están convencidos de una lectura directa de la Vida de Filopemén por parte de Pausanias.

${ }^{67}$ La fecha y la cronología en Errington 1969, p. 250.

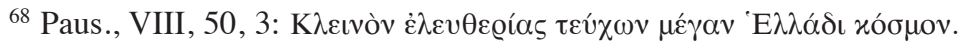

${ }^{69} \mathrm{Plb} ., \mathrm{X}, 21,5-8$.

70 Paus., IV, 23, 8-9. 
que Polibio había elaborado de quien fuese su maestro, en el que se borró las motivaciones políticas de su conflicto con Esparta y las subsumió en el marco de un ideal de lucha panhelénica que legitimara el expansionismo aqueo. ${ }^{71}$ Sería un caso de lo que Candau denomina "prosopopeya memorialista", que comparte muchos elementos con el exemplum de la historiografía antigua, y que lleva a disimular los defectos y magnificar las virtudes de un individuo y, fundamentalmente, a seleccionar aquellos rasgos dignos de imitación..$^{72}$ No es extraño que otros aspectos más cuestionables de su figura, o que simplemente no se amoldaban a la imagen de un benefactor común de los griegos, fueran simplemente elididos del relato histórico. Así, por ejemplo, tras la masacre de Compasio, Polibio dice que Filopemén mandó a ejecutar a 80 líderes espartanos, mientras que Aristócrates señala que fueron unos 350. Lo más llamativo, con todo, es que, aunque Pausanias consultó la obra de Polibio, y probablemente una tradición común a la de Plutarco, mencionaba solamente que 300 individuos habían sido expulsados del Peloponeso. ${ }^{73}$ Otros testimonios parecen mostrar, al menos según la perspectiva de David Golan, que Filopemén, más que estar abocado a un proyecto panhelénico, estaba preocupado por someter a otros griegos a la Confederación Aquea. ${ }^{74}$

No resulta llamativo, por lo tanto, y en consonancia con la prosopopeya de Filopemén y otros líderes aqueos como Arato, que Pausanias exacerbara la visión edulcorada del progreso territorial de la Confederación Aquea como un proceso carente de conflictos, excepto contra Esparta, que, a su vez, era vista como una fuerza contraria a la libertad. ${ }^{75}$ Incluso una acción controvertida para la opinión pública griega como había sido el saqueo de Mantinea y la esclavización de su población por Antígono Doson y Arato, es elidida por Pausanias. ${ }^{76}$ ¿Cómo designar

${ }^{71}$ Renaud 1971.

${ }^{72}$ Candau 2008, pp. 140-141.

73 Plutarco (Phil., 16, 4) señala tanto las cifras de Polibio como las brindadas por Aristócrates (FGrHist 591 F4). Tito Livio (XXXVIII, 33, 10-11) parece aceptar la cifra de Polibio (septemdecim ... sexaginta tres). Los 350 puede ser una exageración proespartana (Errington 1969, p. 145). Cifras de Pausanias (VIII, 51, 3).

${ }^{74}$ Golan 1974.

75 Notablemente, en Paus., VII, 7, 2-3.

${ }^{76} \mathrm{Ib}$., VIII, 8, 11. Polibio (II, 56-58) había tenido que ensayar una defensa de Arato y Antígono por la esclavización en masa de la población de Mantinea, ácidamente criticada por Filarco. Cf. Rostovtzeff 1998, p. 194. 
a Arato como uno de los benefactores comunes de los griegos cuando había esclavizado a una pólis griega? La única explicación posible es que algunos elementos de la historia aquea helenística que el periegeta halló en las Historias de Polibio no se amoldaban sin crear polémica a su propia lectura del pasado griego, en el que los aqueos debían ser vistos como la última fuerza liberadora de Grecia.

La imagen de Filopemén era, por lo tanto, funcional al problema de la libertad griega abordado, puesto que, no sorprendentemente, otro de sus "benefactores comunes de Grecia", Epaminondas, era representado prácticamente en los mismos términos en una inscripción en dísticos elegíacos que había hallado: "que los griegos obtuvieron la libertad gracias a él". Los versos rezaban como conclusión: "mientras toda la Hélade es autónoma en la libertad". ${ }^{77} \mathrm{Ni}$ Filopemén, ni Epaminondas se habían enfrentado militarmente a enemigos externos, sino que ambos combatieron a Esparta y evitaron que sometiera a otros griegos. La amenaza a la libertad griega podía provenir, dentro del pasado panhelénico construido por Pausanias, tanto de una potencia invasora como de una potencia griega. Por ello, Filopemén y Epaminondas merecían estar a la altura de grandes héroes griegos del pasado como Milcíades o Leónidas.

\section{Los líderes aqueos y el fin de la libertad griega}

Como Swain ha puesto de relieve, en el recurso al pasado por parte de los intelectuales griegos bajo dominio romano existía una estructura ideológica definida, pues los modelos o figuras individuales arquetípicas del pasado eran funcionales a las nuevas élites cívicas, que buscaban asociarse a aquellas y apuntalar su legitimidad para mandar sobre la base de compartir ciertos rasgos de carácter. ${ }^{78} \mathrm{Al}$ mismo tiempo, la historia constituía un vehículo de comunicación importante dentro de la élite griega cultivada de los $\pi \varepsilon \pi \alpha \iota \delta \varepsilon v \mu \varepsilon ́ v o ı$, ya que, en líneas generales, todos ellos conocían los acontecimientos básicos del pasado y tenían a menudo ideas similares sobre su importancia y sentido. ${ }^{79}$ Las figuras

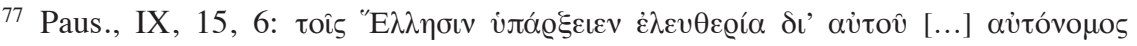

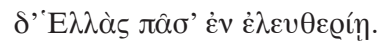

${ }^{78}$ Swain 1996, p. 72.

${ }^{79}$ Pretzler 2007, p. 74. 
individuales del pasado griego, como se ha observado en el caso de los benefactores comunes de Grecia, importaban a Pausanias porque le permitían presentar a su público de la élite modelos de comportamiento, en los cuales éste podía reflejarse e inspirarse. El caso del comportamiento de los líderes de la guerra aquea nos permitirá explorar esta cuestión y la relación de la élite con el tópico de la libertad griega.

En la actualidad existe un consenso en torno a que la fuente consultada por Pausanias para componer su relato de la guerra aquea fue Polibio. La tesis del uso de una fuente intermedia, propuesta en el siglo XIX por Bartholomäus Baier y Curt Wachsmuth, ha quedado actualmente obsoleta dados sus supuestos hoy dejados de lado:

1) El "autor intermedio" no habría compartido con Polibio una supuesta "römerfreundliche Gesinnung" o disposición amistosa hacia los romanos, puesto que el relato de Pausanias sería más favorable a los aqueos;

2) simpatía por los atenienses, no compartida por Polibio;

3) animosidad general contra los reyes macedonios, que en Polibio no sería tan monolítica;

4) creencia en la retribución divina por las acciones. ${ }^{80}$

Según esta postura, todo ello indicaría el uso de una fuente aquea independiente; sin embargo, ya Herman Ebeling mostró que los cuatro ítems, más que pertenecer a una fuente desconocida, eran características propias de Pausanias y que este supuesto de la no consulta directa de Polibio descansaba exclusivamente en los prejuicios sobre el carácter no-creativo de la narración de la Periégesis. ${ }^{81}$

Podemos constatar que tanto en el relato de Pausanias, como en el de Polibio, los líderes aqueos son los grandes responsables del fin de este experimento griego de unión y defensa de la libertad: "Y cuando a duras penas, como de un árbol dañado y seco en su mayor parte, retoñó de la Hélade la Confederación Aquea, la impericia de sus jefes la cortaron mientras todavía estaba creciendo". ${ }^{82}$ Es interesante que esta reflexión cerrara una digresión particular sobre Acaya en la que se ligaba su derrota a manos de los romanos con la historia de Grecia a partir del siglo IV a. C. que se caracterizaba porque "ninguno de los griegos

${ }^{80}$ Baier 1885; Wachsmuth 1887.

${ }^{81}$ Ebeling 1914, p. 141. Sobre la incapacidad creativa de Pausanias: Habicht 1985 , pp. 165-175.

${ }^{82}$ Paus., VII, 17, 2. 
tenía la hegemonía", 83 dado que Esparta, Atenas y Tebas habían sufrido graves descalabros. La hegemonía pasó finalmente a los aqueos, pues a la autoridad que los romanos colocaron en territorio griego "lo llaman gobernador no de Grecia sino de Acaya porque sometieron a los griegos a través de los aqueos que entonces estaban a la cabeza del mundo griego" ${ }^{84} \mathrm{La}$ "impericia de sus jefes" provocó, por lo tanto, la pérdida de la libertad no sólo para los aqueos, sino también para los griegos en su conjunto.

Sin embargo, esta responsabilidad atribuida a los líderes políticos aqueos $^{85}$ debe considerarse sólo como el último acto de una serie de maniobras que habrían saboteado internamente la libertad griega a lo largo de la historia desde época clásica. Pausanias presenta modelos positivos y negativos de líderes griegos, prestando atención principalmente a su comportamiento responsable, o no, respecto a la libertad y la autonomía griegas. Los últimos líderes aqueos son importantes, por lo tanto, por lo que representan para su clave de lectura histórica.

La traición es lo más visible entre estas acciones que desde la perspectiva del periegeta socavaron la libertad, como se observa en su narración sobre Calícrates. ${ }^{86} \mathrm{Su}$ fuente evidente es Polibio, lo que lo hace describir a aquel líder aqueo como el iniciador de los males para su pueblo. ${ }^{87}$ Pero Pausanias enmarca la acción de Calícrates dentro de una historia más vasta de la traición entre los griegos que se remonta a la época clásica. Así, enumera la acción de los trierarcos samios, la de los prominentes ciudadanos eretrios, tebanos y tesalios en los enfrentamientos contra los persas, las de los amigos de Lisandro y las de muchos ciudadanos griegos en favor de Filipo II. Su relato de los tratos entre Démades y Antípatro en la guerra Lamíaca es central:

Cuando los griegos sufrieron la derrota de Lamia, Antípatro se esforzaba en pasar a la guerra de Asia, y quería concluir rápidamente la paz y no le importaba nada si iba a dejar libres a Atenas y a toda Hélade (عi A A

\footnotetext{
${ }^{83} \mathrm{Ib} ., \mathrm{VII}, 6,8$.

${ }^{84} \mathrm{Ib} .$, VII, 16, 10.
}

${ }^{85}$ Pausanias subraya fundamentalmente el carácter execrable de Calícrates (VII, 11, 2:

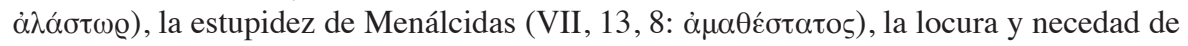

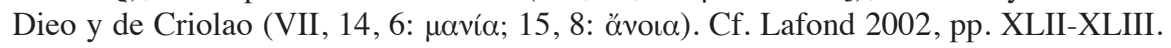

${ }^{86}$ Paus., VII, 10, 1-12.

${ }^{87}$ Cf. Plb., XXIV, 10, 8. 


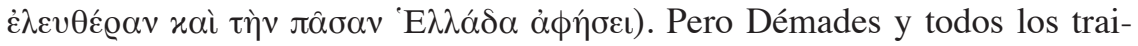
dores que había en Atenas convencieron a Antípatro de que no tuviese nin-

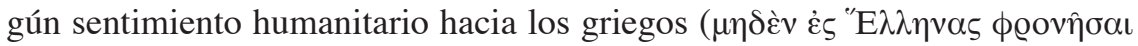
$\phi \iota \lambda \alpha ́ v \theta \varrho \omega \pi \mathrm{ov}), \mathrm{y}$, asustando al pueblo de los atenienses, fueron los culpables de que fueran introducidas guarniciones en Atenas y la mayoría de las demás ciudades. Confirma mi opinión lo siguiente: los atenienses, en efecto, después del infortunio en Beocia no se convirtieron en súbditos de Filipo, aunque fueron apresados dos mil, cuando fueron vencidos en la batalla, y muertos mil. Pero en Lamia cayeron unos doscientos, y no más, y sin embargo fueron

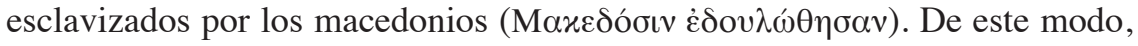
nunca se vio libre la Hélade de la plaga de los traidores; y a los aqueos un aqueo, Calícrates, de ese modo, los sometió totalmente a los romanos

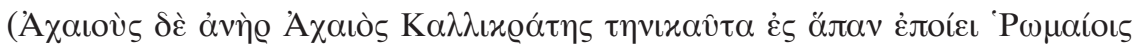

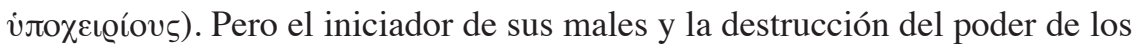
macedonios por los romanos fue Perseo. ${ }^{88}$

Las situaciones históricas no son completamente análogas, pues Atenas había sido derrotada militarmente por Antípatro, mientras que la Confederación Aquea era aliada de Roma. El resultado, sin embargo, fue el mismo, pues los responsables de la pérdida de la libertad habían sido los propios líderes que traicionaron a sus respectivas patrias. Esto se interpretaba como una constante del pasado griego: "el traicionar a su patria y a sus conciudadanos por ganancias particulares, que nunca en todo el tiempo había faltado a la Hélade" ${ }^{89}$ En ese sentido, también recurrir a una fuerza exterior para hacerse con el poder es motivo de crítica en varios pasajes de la obra. ${ }^{90}$

Otro aspecto central de la crítica a los líderes griegos es su responsabilidad en la rivalidad y guerra incesante entre las póleis, lo que debilitó a Grecia e impidió que pudiera ofrecer un frente panhelénico común a los invasores, tal como se pone de relieve en el momento del ascenso de la Confederación Aquea. ${ }^{91}$ En su pasaje sobre los "benefactores comunes de los griegos", además, no incluye a ninguno de los líderes de la guerra

${ }^{88}$ Paus., VII, 10.4-5.

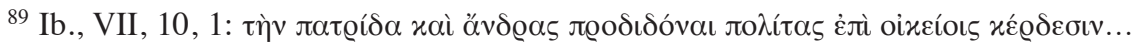

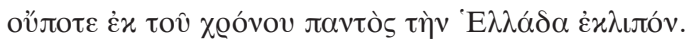

${ }^{90}$ Cf. ib., I, 23 , 4; II, 21, 8; III, 4, 2; 5, 1; 8, 4; IV, 28, 4; V, 5, 1; VII, 7, 5; 10, 1-5; 27, 7; X, 34, 3; etc.

${ }^{91}$ Ib., VII, 6, 8-9. 
del Peloponeso, que "se podría decir que eran asesinos por su propia mano y casi los que hundieron a la Hélade". ${ }^{2}$ Queronea tampoco estaba al margen de esta interpretación, puesto que Filipo II, si bien había derrotado a los griegos en el campo de batalla, su victoria fue anticipada por las acciones irresponsables de los líderes griegos que se habían enzarzado en guerras ininterrumpidas.

En efecto, los Imperios persa, macedonio y romano parecen aprovecharse de las rivalidades y de la falta de solidaridad panhelénica, algo que Pausanias es incapaz de comprender. En realidad, esto era perfectamente natural porque nunca había existido una "nacionalidad" griega, ni tampoco ello constituyó una preocupación para los antiguos griegos, sino sólo para los historiadores europeos del siglo XIX que se preguntaban por qué los griegos fallaron en construir una nación. ${ }^{93}$ Ciertamente existió una identidad cultural griega desde época arcaica, que generó cierto grado de pertenencia e identidad, pero que no avanzó más allá. ${ }^{94}$ La identidad de los ciudadanos con su pólis había primado siempre, aunque Pausanias, escribiendo tras la organización del Panhellenion en época de Adriano, pensaba en una identidad griega de fronteras más vastas. Su incomprensión se advierte, por ejemplo, en su evaluación de la alianza entre Esparta y Creso, rey de Lidia: “y cuando Creso les envió regalos, fueron los primeros que se hicieron amigos del bárbaro, después de que había esclavizado a los demás griegos de Asia y a todos los dorios que habitan en el continente cario". 95

La falta de solidaridad y unión entre los griegos se advierte en cada una de las luchas colectivas que éstos entablaron por su libertad, en las que algunos de ellos no participaron debido a sus rivalidades con otros griegos. ${ }^{96}$ Pausanias no ahorraba en consecuencia recriminaciones al respecto, por ejemplo, en el caso de los arcadios, porque no habían participado en Queronea y Lamia: "De que Filipo, hijo de Amintas, y el poder de los macedonios creciera fue causa, sobre todo, el odio de los arcadios contra los espartanos, y los arcadios no participaron en Que-

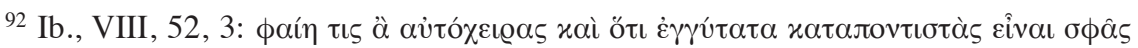

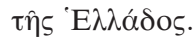

${ }^{93}$ En general, Walbank 1951.

${ }^{94}$ Cf. Hall 2005.

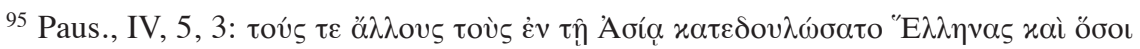

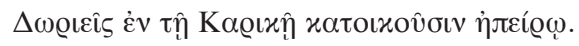

${ }^{96} \mathrm{Ib} ., \mathrm{IV}, 28,2$; V, 4, 9; VII, 6, 4; VIII, 6, 3. 
ronea con los griegos, ni tampoco en el combate de Tesalia". ${ }^{97}$ Estos particularismos eran objeto de crítica como un componente disolvente del panhelenismo.

Una vez más repetimos: la óptica de Pausanias es, por lo tanto, panhelénica y no se preocupa por entender las circunstancias históricas concretas del pasado griego, es decir, las serias rivalidades entre póleis, sino que juzga el pasado sobre parámetros acordes con su propio ideal panhelénico contemporáneo. Dentro de esta estructura ideologizada de lectura del pasado es fácil justificar, por las rivalidades y mezquindades, el derrumbe de Grecia. Desconociendo por momentos, aunque no en el caso de Esparta, la naturaleza opresiva de las hegemonías de las póleis griegas, podía entonces afirmar, por ejemplo, "que la derrota en Queronea fue un desastre para todos los griegos". ${ }^{98}$ Muchos griegos se habían beneficiado del apoyo de Filipo II, sobre todo aquellos del Peloponeso, pero Pausanias desconoce esta situación.

¿Cuál era la postura de Pausanias frente al dominio romano? Uno de los pasajes más polémicos de la Periégesis en el que el autor emite, posiblemente, un juicio negativo sobre la expansión romana a Grecia es VIII, 27, 1. Allí muestra cierto paralelo con la calificación de Que-

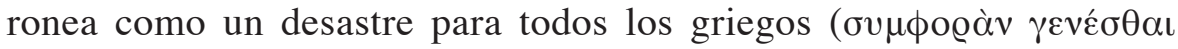

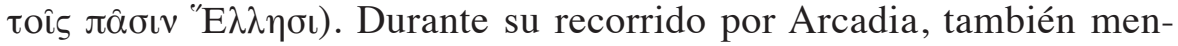

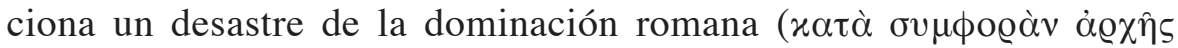
$\left.\tau \hat{\Upsilon} \varsigma{ }^{\circ} \mathrm{P} \omega \mu \alpha{ }^{\prime} \omega v\right)^{99}$ relacionado con el movimiento de pueblos y la fundación de ciudades. Literalmente, la traducción sería que el movimiento de pueblos había ocurrido "a causa del desastre de la dominación romana".

Sin embargo, a comienzos del siglo XIX, Etienne Clavier enmendó

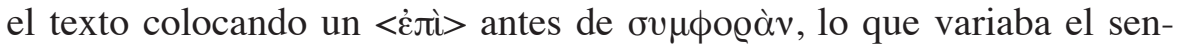
tido a "como resultado de un desastre que ocurrió durante el dominio romano". ${ }^{100}$ Casi todos los editores modernos han aceptado esta conjetura gracias a la autoridad de Jonas Palm, que fue un defensor a ultranza

${ }^{97} \mathrm{Ib} .$, VIII, 27, 10.

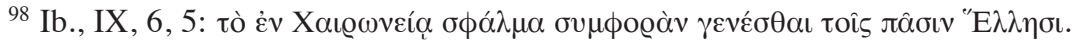

${ }^{99}$ Ib., VIII, 27, 1.

${ }^{100}$ Clavier 1814-1821. Como señala Hutton (2008, p. 630, n. 34), Clavier no ofrece ningún motivo para esta enmienda, además, ninguna edición del texto anterior a 1959 la incluye. 
de la validez de la enmienda textual. ${ }^{101} \mathrm{Su}$ tesis era que Pausanias no atribuía la decadencia de los griegos a los romanos, sino a los macedonios y que, además, era un observador neutral de las intervenciones romanas en Grecia. La enmienda contribuía, por lo tanto, a reforzar el argumento del erudito sueco. ${ }^{102}$

Ewen Bowie fue uno de los primeros en negar la validez de la enmienda. ${ }^{103}$ Más recientemente, William Hutton ha demolido sistemáticamente los dos supuestos principales sobre los que Palm se apoyaba. ${ }^{104}$ Por una parte, resulta bastante claro que el pasaje, tal como fue transmitido, tiene sentido y, por otra, ayuda a entender la compleja naturaleza de la actitud político-cultural de Pausanias hacia el dominio romano. Pero a qué clase de "desastre" alude. La respuesta de Palm, de que se trataba de algún tipo de desastre natural, ha sido rebatida por Swain, por lo que parece claro que el desastre estaría explícitamente relacionado con efectos del dominio romano sobre Grecia. ${ }^{105}$ Hutton ha llamado la atención sobre los sinecismos forzados impulsados por Augusto en Patrás y Nicópolis, así como también el repoblamiento de Corinto. ${ }^{106}$

Nos gustaría argumentar en favor de este último caso, pero también advertir que la destrucción de Corinto tiene un sentido particularmente importante en el marco de su relato de la Guerra Aquea. Como Elsner ha puesto de manifiesto, la Periégesis es un "compendio cuidadosamente estructurado de regiones elegidas, formado y ordenado a través del viaje en una narrativa continua y que a través de 'digresiones' (históricas, religiosas, mitológicas, histórico artísticas, etnográficas) transmitía un cuidadoso retrato, una ideología deliberada, de 'Grecia'". ${ }^{107}$ No pueden tomarse, por lo tanto, pasajes aislados sin relacionarlos, puesto que se

${ }^{101}$ Palm 1959, pp. 63-74. Todas las ediciones modernas posteriores a 1959, excepto una, adoptan la enmienda del texto de Clavier. Moggi y Ossana (2003), en cambio,

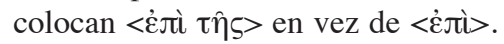

${ }^{102}$ La hostilidad, en Gurlitt 1890, p. 87, n. 43; Regenbogen 1956, pp. 1069-1070. Habicht (1985, p. 120) plantea que, más que hostilidad, Pausanias "se muestra lleno de resentimiento y animosidad".

103 Bowie 1994, p. 217.

${ }^{104}$ Hutton 2008, pp. 630-631.

105 Swain 1996, pp. 353-354.

${ }^{106}$ Hutton 2008, p. 625. Nicópolis: Paus., V, 23 , 3; VII, 18, 8-9; X, 38, 4; Patrás: VII, 17,$5 ; 18,7 ; 27,1$. Corinto, ver más adelante. Cf. Swain 1996, pp. 354 ss.

${ }^{107}$ Elsner 2001, p. 6. 
trata de una cuidadosa obra. Así, puede establecerse una conexión con un pasaje del libro V:

Los arcadios desde el comienzo hasta hoy, han continuado en posesión de su tierra. Los restantes han venido de fuera. En efecto, los actuales corintios fueron los últimos en llegar de los peloponesios, y desde que recibieron del emperador la tierra hasta mi época han pasado doscientos diecisiete años. ${ }^{108}$

El caso de Corinto, que ha sido denominado "el centro de la Romanitas en Grecia", 109 es significativo. Aunque en el siglo II d. C. se produjo, gracias a las medidas implementadas por Adriano, una presión hacia la adopción del griego en la ciudad, la misma siguió siendo un punto clave del dominio romano en el oriente griego. ${ }^{110}$ Un contemporáneo de Pausanias, Apuleyo, decía sobre Corinto caput est totius Achaiae provinciae ("es la cabeza de toda la provincia de Acaya"). ${ }^{111}$ Como sugiere Karim Arafat, es probable que el propio periegeta considerara que Corinto era, en efecto, el centro del influjo romano en Grecia. ${ }^{112}$ En ese sentido, existen algunos indicios de que la élite corintia, a partir del siglo II d. C., trató activamente de asociarse al pasado helénico, como permite suponer el hecho de que Favorino hablara del carácter helénico de los nuevos pobladores. ${ }^{113}$ Quizá la referencia en Pausanias a los antiguos sacrificios en el templo de Deima ("el Terror"), que, "después de que Corinto fue destruido por los romanos y los antiguos corintios murieron", dejaron de ser realizados por los nuevos colonos, apunte a marcar la ruptura cultural entre ambos asentamientos. ${ }^{114}$ Se trataría realmente de una estrategia de memoria a contrapelo de la de la élite corintia, puesto que así, al menos, nos parece que puede interpretarse un pasaje en el que Pausanias busca marcar la ruptura cultural con el pasado de Corinto: "Más arriba del teatro hay un santuario de Zeus Capitolino en lengua de los romanos;

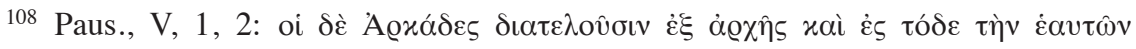

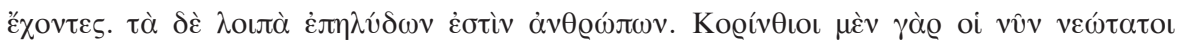

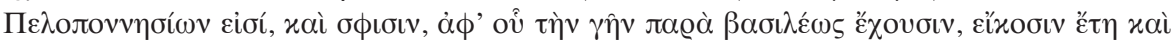

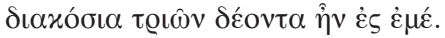

${ }^{109}$ Cartledge y Spawforth 1989, p. 104; Alcock 1993, p. 156.

110 Alcock 1993, p. 169.

111 Apul., Met., X, 18.

${ }^{112}$ Arfat 1996, pp. 90, 109-112.

${ }^{113}$ D. Chr., XXXVII, 1; 26.

${ }^{114}$ Paus., II, 3, 7; cf. Hutton 2008, p. 148. 
en lengua griega sería llamado Corifeo". ${ }^{115}$ La Corinto actual no posee, por lo tanto, ni la lengua, ni los ritos de la antigua y difícilmente pueda considerársela "griega".

Pero la discontinuidad no sería sólo cultural, sino incluso biológica. Pausanias establece una marcada distinción entre los "actuales corin-

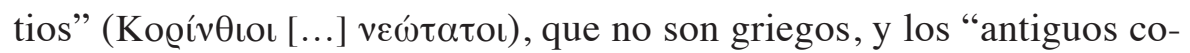

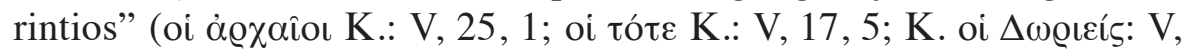
10, 5). ${ }^{116}$ Los habitantes de la Laus Iulia Corinthus, fundada en el 44 a. C., son considerados recién llegados sin vínculos con la antigua pólis, es decir: "En Corinto no vive ya ninguno de los antiguos corintios, sino colonos enviados por los romanos". ${ }^{117}$ En II, 3, 1, el periegeta introduce la siguiente noticia: "Por encima del ágora hay un templo de Octavia, hermana de Augusto, que fue emperador de los romanos después de César,

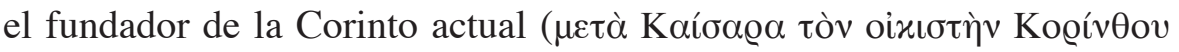

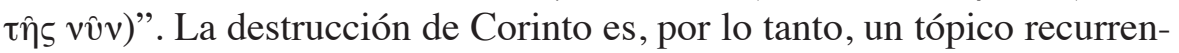
te, así como también lo es el hecho de que la nueva pólis no tenga nada que ver con la anterior. Su destrucción en el marco de la Guerra Aquea es explícitamente recordada al inicio del libro II, lo que puede ser significativo para ligarla con su carácter más nuevo que el de Megalópolis. En definitiva, el dominio romano abría una nueva realidad para Grecia:

En Corinto no vive ya ninguno de los antiguos corintios, sino colonos enviados por los romanos. La causa de esto fue la Confederación Aquea, pues como los corintios eran miembros de ella, también participaron en la guerra contra los romanos, que Critolao, elegido estratego de los aqueos, hizo estallar, persuadiendo a los aqueos y a la mayoría de los de afuera del Peloponeso de que se rebelasen. Cuando los romanos vencieron en la guerra, despojaron a todos los griegos de las armas y derribaron las murallas de todas las ciudades que estaban fortificadas. Pero Mumio, que estaba al mando del ejército romano, asoló Corinto, y dicen que después la repobló César, que fue el que estableció el actual régimen político de Roma; y también reconstruyó Cartago durante su mandato. ${ }^{118}$

115 Paus., II, 4, 5.

${ }^{116}$ No se entiende la afirmación de Elsner (1992, p. 15) sobre la "grecidad" adquirida por los nuevos corintios: "En virtud de estar en aquel lugar, de acuerdo a la definición pausaniana, estas personas habían llegado a ser 'griegas'; el lugar mismo les había impartido su identidad".

${ }_{117}$ Paus., II, 1, 2; cf., también, II, 3, 7.

118 Paus., II, 1, 2. 
El contexto del pasaje es fundamental para comprender el xat⿳亠े

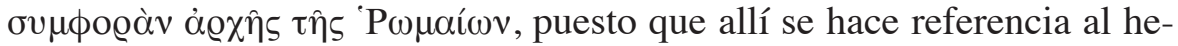
cho de que Megalópolis era la ciudad más reciente no sólo de Arcadia, fundada tras la batalla de Leuctra, quizá en 368 a. C., sino también de toda Grecia," 119 "excepto aquellas cuyos habitantes cambiaron de lugar como resultado del desastre de la dominación romana". La vinculación entre distintas historias presentes en digresiones, sobre los aqueos, se vuelve así central para comprender la actitud de Pausanias frente a Roma en VIII, 27, 1. Recientemente, Juan Pablo Sánchez Hernández ha propuesto una interpretación del pasaje y una traducción, "como consecuencia de la crisis de gobierno de Roma", centradas en la realidad histórica de la lucha política en el Mediterráneo oriental durante la crisis de la República. ${ }^{120}$ Esta tesis es interesante, pues muestra sensibilidad por la reflexión histórica de Pausanias que, de ese modo, habría sido capaz de enlazar la historia griega con la realidad de la crisis del sistema de gobierno romano, algo también adelantado por Johanna Akujärvi. ${ }^{121}$ Sin embargo, la evidencia es débil y parece más conveniente relacionar directamente la idea de desastre con la imposición del dominio romano sobre Grecia tras la derrota de la Confederación Aquea. En el caso de Corinto y de los corintios, esto es claro, pues llevó a la destrucción de su pólis, pero nos interesaría, además, sumar el caso de los arcadios.

Este desastre del dominio romano se sitúa espacial y narrativamente en Arcadia. En el mismo libro Pausanias escribe: "De todas las ciudades que la tierra ha mostrado en el continente y en las islas Licosura es la más antigua y la primera a la que contempló el sol". ${ }^{122}$ Así como ésta era la más antigua, Megalópolis era la más moderna, y ambas se ubicaban en la misma región. Pero lo cierto es que la segunda estaba ya en decadencia, así como gran parte de las ciudades arcadias, según el propio autor. ${ }^{123}$ Arcadia es, como en gran parte de la literatura clásica, un vestigio del pasado, de un mundo anterior a la llegada de los romanos y, por ello, se muestra como un espacio geográfico-cultural apropiado para re-

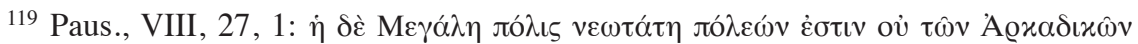

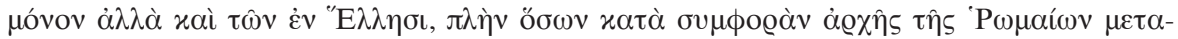
$\beta \varepsilon \beta \eta \dot{x \alpha \sigma ı v ~ o i x i ́ t o e \varepsilon s . ~}$

120 Sánchez Hernández 2008.

${ }^{121}$ Akujärvi 2005, pp. 288-289.

122 Paus., VIII, 38, 1.

${ }^{123}$ Ib., VIII, 33, 1; 27, 7. 
flexionar sobre el impacto de la llegada de éstos, que no sería totalmente negativa para las ciudades de la región como en el caso de Palantio.

Dice Pausanias ${ }^{124}$ que la misma, ligada por "parentesco" a los romanos, experimentó una mejor suerte, puesto que Antonino Pío la elevó de aldea al rango de ciudad y le concedió además libertad y exención de impuestos. En cambio, Pausanias recuerda que los arcadios tomaron parte de manera más entusiasta que otros griegos en la Confederación Aquea $^{125}$ y que sus tropas fueron masacradas en Queronea por Cecilio Metelo. ${ }^{126}$ También cuenta que, aunque Cleómenes III de Esparta devastó Megalópolis, ésta fue restaurada y rehabitada a continuación por los aqueos, ${ }^{127}$ mientras que en época romana se encontraba abandonada y en ruinas. ${ }^{128}$ Ya Polibio mencionaba los problemas demográficos y de tierra de esta ciudad, pero Pausanias omitía esta cuestión en su breve síntesis. De acuerdo con cómo presenta la situación de Arcadia en general, y de Megalópolis en particular, en época romana es difícil no reconocer que para él el dominio romano en Arcadia había sido un verdadero desastre.

Es interesante notar que tanto Corinto como los arcadios se convirtieron en víctimas de los romanos debido a su pertenencia y a su activa participación dentro de la Confederación Aquea. La derrota de ésta, "que entonces estaba a la cabeza del mundo griego", ${ }^{129}$ significó el sometimiento de Grecia y la pérdida de la libertad. Las medidas tomadas por Mumio fueron brutales, entre ellas, la destrucción de Corinto. ${ }^{130}$ Las consecuencias para Arcadia, que también participó activamente, fueron terribles. Dados estos datos es difícil negar que Pausanias interpretara la llegada de los romanos como un "desastre" para Grecia, equiparada en su discurso con la Confederación Aquea. Se trataba simplemente de una lectura del modo dramático en el que Grecia había dejado de ser libre. La situación histórica de imposición del dominio romano había sido traumática, por las duras medidas tomadas de inmediato después de 146 a. C., por los destrozos durante la primera guerra Mitridática, como en

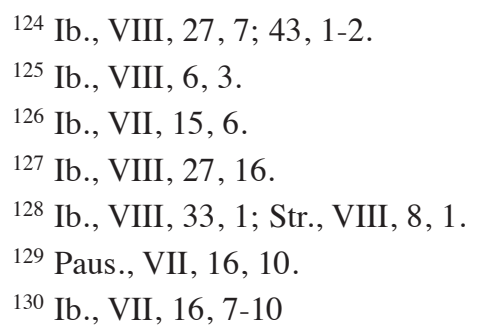


el caso de Tebas, ${ }^{131}$ por la guerra librada en su territorio durante la lucha por el poder entre romanos hasta Accio en 31 a. C. y por los consiguientes movimientos de población ordenados por Augusto a continuación. Con todo, Pausanias reconoce que un emperador romano, Adriano, había hecho florecer de nuevo a Atenas ${ }^{132} \mathrm{y}$, de hecho, a todo el mundo griego excepto a Mégara. ${ }^{133}$ Hay que acordar, por lo tanto, con Palm, en que Pausanias no exhibía una actitud crítica sistemática hacia el dominio romano, sino hacia las acciones particulares de algunos de sus gobernantes y, sobre todo, hacia las circunstancias concretas de la imposición del dominio romano tras la derrota aquea.

Además, la responsabilidad última por el "desastre" griego es atribuida a los propios griegos. ${ }^{134}$ La causa había sido la Confederación Aquea y su líder, Critolao, que convenció a los aqueos y a la mayoría de los de afuera del Peloponeso a rebelarse: ${ }^{135}$ "A este Critolao le dominaba un ardiente e irrazonable deseo de hacer la guerra contra los romanos". ${ }^{136}$ El periegeta no critica per se la guerra, sino, en consonancia con la reflexión polibiana, por sus pocas posibilidades de éxito: "Pero la audacia acompañada de debilidad más bien se podría llamar locura que mala suerte". ${ }^{137}$

Se advierte, sin embargo, una diferencia con la evaluación de Polibio de estos líderes, puesto que Pausanias se mostraba preocupado por los modelos de comportamiento clásico de defensa de la libertad griega frente a la barbarie. Borja Antela Bernárdez explica que "la guerra aparece en el mundo antiguo como el gran examen del carácter [ ...], cualquier vicio o error demostrado en campaña es un síntoma de debilidad

\footnotetext{
${ }^{131}$ Ib., IX, 7, 6.

132 Ib., I, 20, 7.

133 Ib., I, 36, 3.
}

${ }^{134}$ Mauro Moggi (2002, p. 447) apunta sagazmente a la responsabilidad atribuida por el periegeta al embajador C. Sulpicio Galo, enviado para mediar entre Argos y Esparta en 164/3 a. C., que precede a la crisis aquea frente a Roma en casi veinte años, lo cual no encuentra paralelo en Polibio.

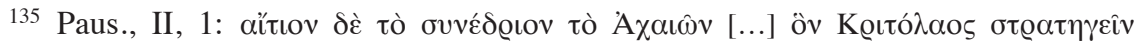

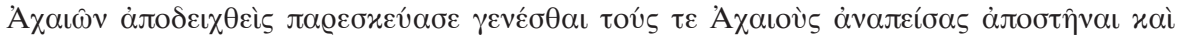

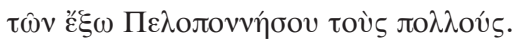

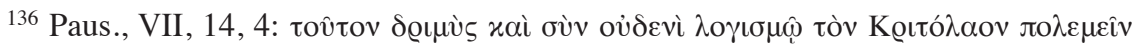

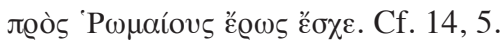

${ }^{137}$ Ib., VII, 14, 6. 
interior". ${ }^{138}$ Pausanias veía a Critolao en consecuencia como un pálido reflejo de los héroes griegos del pasado, que se habían enfrentado con valor a los bárbaros:

Entonces, cuando Critolao se enteró por sus espías de que Metelo y los romanos habían cruzado el Esperqueo, se refugió en Escarfea de los locrios y no se atrevió a apostar a los aqueos en el estrecho que hay entre Heraclea y las Termópilas y a esperar a Metelo, sino que llegó a tal grado de terror que ni siquiera le inspiró mayor confianza el mismo lugar donde los lacedemonios lucharon contra los medos en favor de los griegos y los atenienses realizaron actos de audacia contra los gálatas, en nada menos gloriosos que aquéllos. ${ }^{139}$

Pausanias señala además, tomándolo, sin duda, de Polibio, ${ }^{140}$ que Dieo ordenó la liberación de esclavos. ${ }^{141}$ Sin embargo, el periegeta agrega una interpretación propia, pues dice que el líder aqueo lo hizo: "imitando la decisión de Milcíades y los atenienses antes de la batalla de Maratón”. ¿Pausanias creía que ambas situaciones eran análogas? ¿Estaban los griegos a punto de enfrentarse a la amenaza de ser esclavizados por bárbaros? ¿Eran los romanos "bárbaros”? Susan Alcock ha observado la importancia que tenía en la obra la memoria de la guerra de Troya, las guerras Médicas y la invasión de los gálatas, y podríamos agregar también la resistencia a los reyes macedonios. Esto denotaba un paradigma de rechazo de lo bárbaro y, por lo tanto, "de mantenimiento de una frontera entre griegos y aquellos a los que enfrentan [...] el rechazo de los persas, y de los 'otros' asociados, del suelo griego se vuelve una metáfora para este proceso". ${ }^{142}$ Así se sintetizaría el vínculo imaginario entre persas, celtas y romanos y la incapacidad de Critolao de seguir el ejemplo de los grandes griegos del pasado. ${ }^{143}$

${ }^{138}$ Antela-Bernárdez 2008, p. 312.

${ }^{139}$ Paus., VII, 14, 6. Según la reconstrucción de Gruen (1976), quizá la ofensiva de Metelo desde Macedonia tomara por sorpresa a Critolao, quien sólo había liderado una pequeña avanzadilla para reconquistar Heraclea.

${ }^{140}$ Plb., XXXVIII, 15, 3.

141 Paus., VII, 15, 7.

142 Alcock 1994, p. 257.

${ }^{143}$ Es difícil evaluar el lugar de los romanos dentro de la polaridad griegos/bárbaros. Cf. Swain 1996, pp. 350-352; Bowie 1994, pp. 219-220. 
Como había anunciado Pausanias, esta empresa, aunque hubiera sido llevada a cabo y Critolao, sin acobardarse, hubiera enfrentado a los romanos en las Termópilas, habría sin duda también fallado. La memoria de los actos gloriosos como Maratón no necesariamente conducía a una victoria, como los mesenios habían experimentado frente a los acarnanios. ${ }^{144}$ Sin embargo, actuando como lo habían hecho los "benefactores comunes de la Hélade" en el pasado, podría haber dejado un recuerdo de sí mismo digno de la historia griega, al menos como ésta había sido fabricada por el periegeta, en la cual la defensa de la libertad griega era la dimensión central del pasado y también del presente. En el libro X, llegando al final de su obra, Pausanias llega a Elatea y narra las vicisitudes históricas de esta pólis frente a medos, macedonios, romanos y pónticos y añade una pequeña anécdota contemporánea: "En mi tiempo, los costobocos, en sus correrías por la Hélade, llegaron hasta Elatea. Entonces un tal Mnesibulo reunió en torno a sí una compañía de hombres, y después de dar muerte a muchos bárbaros cayó en la batalla”. ${ }^{145}$

Los costobocos hicieron una pequeña correría por Grecia con alcances limitados, pero Mnesibulo, antiguo vencedor olímpico, demostró con su arriesgada acción que la capacidad griega de heroísmo contra los bárbaros no estaba muerta. ${ }^{146} \mathrm{El}$ focidio Patrón, que organizó a los ciudadanos de Lilea para enfrentar a la guarnición de Filipo V, pertenece a la misma prosopopeya pausaniana. No parece casual, teniendo en cuenta el objetivo de la obra de recordar a los griegos su libertad, que su último libro fuera tan rico en ejemplos. ${ }^{147}$ En efecto, acababa de recordar al joven ateniense Cidias, muerto combatiendo contra los gálatas, ${ }^{148}$ acción directamente comparada con el ataque de Jerjes. ${ }^{149}$ Frente a estos ejemplos, los líderes aqueos no sólo habían sido víctimas de su venalidad, audacia, locura, sino además de su incapacidad de estar a la altura de la defensa de la libertad griega y comportarse como Leónidas, Cidias o, incluso, Mnesibulo.

Un rasgo particularmente vituperado en la obra es la cobardía y el temor a la muerte. Tras ser derrotados una segunda vez los aqueos en el Istmo,

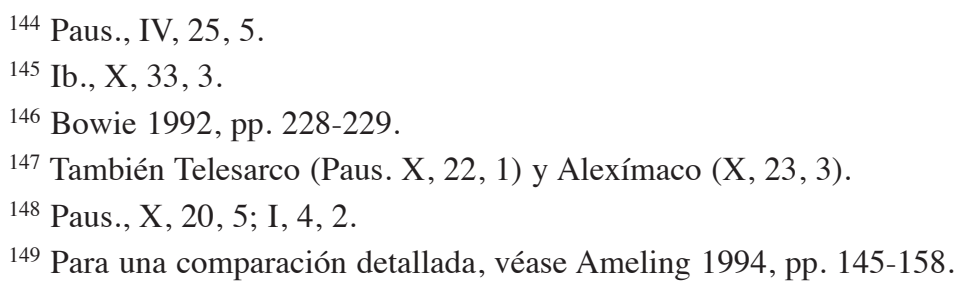


Pausanias ${ }^{150}$ dice que si Dieo se hubiera atrevido a encerrarse en Corinto con los fugitivos de la batalla, los aqueos habrían podido hallar un gesto humanitario de parte de Mumio. En cambio, huyó a Megalópolis, donde mató a su mujer y se envenenó, lo que lleva al periegeta a comparar su acción con la de Calístrato, comandante de caballería ateniense que en Asinaro, durante la campaña en Sicilia, se abrió camino a través de la formación enemiga y puso a salvo a sus jinetes para luego regresar y dar muerte a cinco enemigos antes de caer: "Este conquistó gloria para los atenienses y para sí mismo salvando a los que estaban bajo su mando y muriendo él mismo voluntariamente". ${ }^{151}$ Dieo mostró, en cambio, amor al dinero y cobardía ante la muerte semejante a la de Menálcidas, que había metido en el brete de la guerra contra los aqueos a los espartanos y, no hallando solución, había tomado también veneno. ${ }^{152}$ Pausanias también da a entender que Critolao quizá se habría suicidado, ${ }^{153}$ por lo que el contraste no sólo con Calístrato, sino también con Mnesibulo se hace por demás evidente. Los líderes aqueos no fueron dignos de semejante empresa por la libertad de Grecia y eran definidos, por lo tanto, como anti modelos para la élite griega.

\section{A modo de cierre}

El tópico de la libertad es recurrente en la obra de Pausanias. Esto podría ser sorprendente en un autor que escribía en el tercer cuarto del siglo II d. C., cuando el dominio romano en Grecia estaba ya consolidado, pero, de hecho, este tema está perfectamente en sintonía con el panhelenismo de su época. ${ }^{154} \mathrm{El}$ periegeta recurre a la historia griega clásica, pero también, y a diferencia de muchos de sus contemporáneos, a la helenística, para abordar las actitudes colectivas de los griegos frente a la defensa de la libertad amenazada por fuerzas extranjeras e internas. Su evaluación es que, pese a los numerosos actos de heroísmo llevados a cabo por los griegos en el pasado, la libertad griega estaba condenada

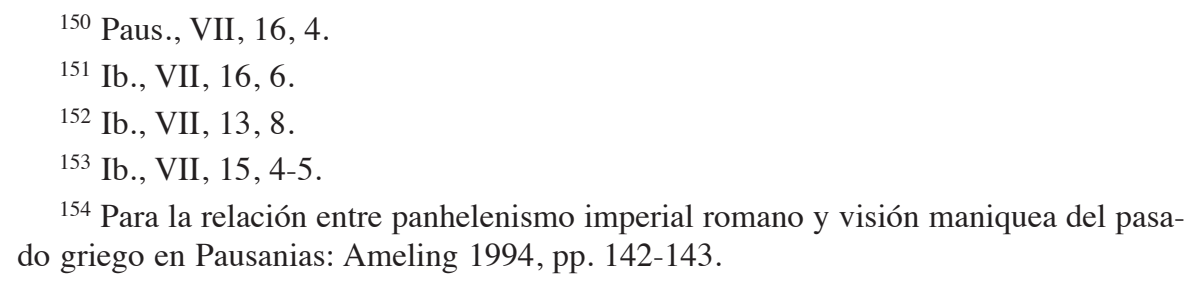


de antemano por el carácter endémico de las rivalidades entre póleis y por la incompetencia de sus líderes políticos. Sólo unos cuantos griegos habían sido capaces de comportarse como benefactores comunes de los griegos.

Su fabricación del pasado griego muestra, por lo tanto, poca sensibilidad por comprenderlo, tratando, por el contrario, de amoldarlo a su ideología panhelénica. En sintonía con esta apropiación y domesticación del pasado, la historia de la Confederación Aquea es colocada como el último eslabón en la cadena histórica de la lucha por la libertad griega y, en ese sentido, su desarrollo del relato sobre la Guerra Aquea parece responder a este objetivo en tanto que explica a los griegos la razón de la pérdida de su libertad. Su explicación tiene en cuenta la acción de Roma como potencia imperialista, pero, a su vez, acentúa las contradicciones estructurales que los griegos habían tenido a lo largo de su historia.

Por lo tanto, es difícil ver a Pausanias como un autor hostil al dominio romano, aunque sí como un intelectual interesado por el pasado que pensaba que hubiera sido mejor que Roma jamás llegara. Su recurso a la invención de un pasado griego clásico y helenístico permitió al periegeta brindar a su público griego claves para racionalizar la pérdida de la libertad como resultado lógico de sus propias fallas y, al mismo tiempo, para brindar modelos que permitieran a la élite griega de su tiempo identificarse. En el pasado hubo griegos que se mostraron dignos de ser tales, como en el caso de Olimpiodoro y de los atenienses a quienes les vino

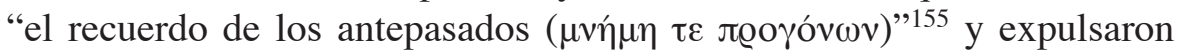
a los macedonios, y otros como los líderes aqueos que fueron incapaces de inspirarse en el recuerdo de las gestas de Maratón o Termópilas. Es-

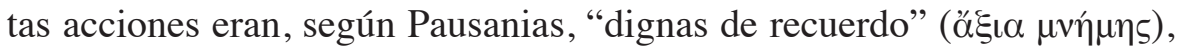
para bien o para mal. Si los griegos eran capaces de recordar estas acciones de los grandes hombres, y cómo las mismas habían contribuido a su libertad, entonces, podían seguir siendo griegos aunque estuvieran dominados por Roma. El ejemplo de Mnesibulo y su pequeña gesta contra los costobocos muestra de manera patente que el recurso al pasado no era un simple alarde de erudición por parte del periegeta sino una muestra de su compromiso con el presente.

155 Paus., I, 26, 1. 


\section{BIBLIOGRAFÍA}

\section{Fuentes}

Pausania, Guida della Grecia, libri I-X, edición de Domenico Musti et al., Milano, Arnoldo Mondadori (Fondazione Lorenzo Valla), 1982-2012.

Pausanias, Descripción de Grecia, libros I-X, introducción, traducción y notas de M. C. Herrero Ingelmo, Madrid, Gredos (Biblioteca Clásica Gredos), 1993.

\section{Estudios}

AkujÄrvi, Johanna, Researcher, Traveller, Narrator: Studies in Pausanias' Periegesis, Stockholm, Almqvist \& Wiksell International, 2005 (Studia Graeca et Latina Lundensia, 12).

Alcock, Susan, Graecia Capta. The Landscapes of Roman Greece, Cambridge, Cambridge University Press, 1993.

_, "Landscapes of Memory and the Authority of Pausanias", en Bingen 1994, pp. 241-267.

-, "The Peculiar Book IV and the Problem of the Messenian Past", en Alcock, Cherry y Elsner 2001, pp. 142-153.

-, J. CherRY y J. Elsner (eds.), Pausanias: Travel and Memory in Roman Greece, Oxford, Oxford University Press, 2001, pp. 142-153.

AMELING, Walter, "Pausanias und die hellenistische Geschichte", en Bingen 1994, pp. 117-160.

ANTELA-BERnÁRDEZ, Borja, "Vencidas, violadas, vendidas: Mujeres griegas y violencia sexual en asedios romanos", Klio, 90 (2), 2008, pp. 307-322.

Arafat, Karim, Pausanias' Greece. Ancient Artists and Roman Rulers, Cambridge, Cambridge University Press, 2004.

BAIER, Bartholomäus, Studien zur Achaeischen Bundes-Verfassung, InauguralDissertation vorgelegt der Philosophische Facultät der Universität Würzburg, Würzburg, 1885.

Bearzot, Cinzia, "L'epigramma come fonte storica in Pausania", en L. Belloni, G. Milanese y A. Porro, Studia classica Johanni Tarditi oblata, vol. I, Milán, Vita e Pensiero, 1995 (Biblioteca di Aevum Antiquum, 7), pp. 695-710.

-, Storia e storiografia ellenistica in Pausania il periegeta, Venezia, il Cardo, 1992.

Bingen, J. (dir.), Pausanias historien, Gèneve, Vandoeuvres, 1994 (Entretiens sur l'Antiquité Classique de la Fondation Hardt, 41).

Bowersock, Glen, "The Mechanics of Subversion in the Roman Provinces", en A. Giovannini (dir.), Opposition et résistances a l'Empire d'Auguste a Trajan, Genève, Vandoeuvres, 1987 (Entretiens sur l'Antiquité Classique de la Fondation Hardt, 33), pp. 291-317. 
BowIE, Ewen, "The Greeks and their past in the second sophistic", en M. Finley

(ed.), Studies in ancient society, London, Routledge, 1974, pp. 166-209.

—, "Past and Present in Pausanias", en Bingen 1994, pp. 207-230.

Candau, Joël, Memoria e identidad, Buenos Aires, Del Sol, 2008.

Cartledge, Paul y Antony Spawforth, Hellenistic and Roman Sparta: A Tale of Two Cities, London, Routledge, 1989.

Chamoux, François, "Pausanias géographe", en R. Chevallier (ed.), Mélanges $R$. Dion, París, 1974 (Caesarodunum 9 bis).

Clavier, Étienne, Description de la Grèce de Pausanias, Paris, Eberhart, 1814-1821.

De Romilly, Jacqueline, Thucydide et l'impérialisme athénien, París, Les Belles Lettres, 1947.

DMitriev, Sviatoslav, The Greek Slogan of Freedom and Early Roman Politics in Greece, Oxford, Oxford University Press, 2011.

Dyson, Stephen, En busca del pasado clásico. Una historia de la arqueología del mundo grecolatino en los siglos XIX-XX, Barcelona, Ariel, 2008.

Ebeling, Hermann, "Pausanias as an Historian", The Classical Weekly, 7 (18), 1914, pp. 138-141.

ELSNER, Jás, “A Greek Pilgrim in the Roman World", $P \& P, 135,1992$, pp. 3-29.

- , "Structuring 'Greece': Pausanias's Periegesis as a Literary Construct", en Alcock, Cherry y Elsner 2001, pp. 3-20.

ERrington, Robert, Philopoemen, Oxford, Clarendon Press, 1969.

FORTE, Bettie, Rome and the Romans as the Greeks saw them, Rome, American Academy in Rome, 1972 (Papers and Monographs, 24).

Frazer, James, Pausanias's Description of Greece, vol. II, Commentary on book 1: Attica, London, MacMillan, 1913.

Golan, David, "Philopoemen immodicus and superbus and Sparta", SCI, 1, 1974, pp. 29-39.

GruEN, Erich, “The origins of the Achaean War", JHS, 96, 1976, pp. 46-69.

GuRLITT, Wilhelm, Über Pausanias, Graz, Leuschner \& Lubensky, 1890.

Habicht, Christian, Pausanias' Guide to Ancient Greece, Berkeley, University of California Press, 1985 (Sather Classical Lectures, 50).

Hall, Jonathan, Hellenicity. Between Ethnicity and Culture, Chicago, University of Chicago Press, 2005.

Hutton, William, Describing Greece. Landscape and Literature in the Periegesis of Pausanias, Cambridge, Cambridge University Press, 2005.

—, “The Disaster of Roman Rule: Pausanias VIII.27.1”, CQ, 58 (2), 2008, pp. 622637.

Konstan, David, "Seeing Greece with Pausanias", en F. Mestre y P. Gómez Cardó (eds.), Homo Romanus Graeca Oratione, Barcelona, Universidad de Barcelona, 2014, en prensa.

LAFOnd, Yves, "Notice”, Pausanias, Description de la Grèce, Livre VII, L'Achaie, Paris, Les Belles Lettres, 2002, pp. IX-LXVII.

- , "Pausanias et l'histoire du Péloponnese depuis la conquête romaine", en Bingen 1994, pp. 167-198. 
Moggi, Mauro, "Pausania e Roma (Nota di lettura a VIII 27, 1)", Gerión, 20 (1), 2002, pp. 435-449.

- y Massimo Ossana, "Nota Introduttiva al libro VIII", en Pausania. Guida della Grecia. Libro VIII L'Arcadia, Milano, Arnoldo Mondadori Editore, 2003 (Fondazione Lorenzo Valla), pp. IX-XLIX.

Musti, Domenico, "La struttura del discorso storico in Pausania", en J. Bingen 1994, pp. 9-34.

—, "L'itinerario di Pausania: dal viaggio alla storia", QUCC, 17 (2), 1984, pp. 7-18.

PALM, Jonas, Rom, Römertum und Imperium in der griechischen Literatur der Kaiserzeit, Lund, Gleerup, 1959 (Acta Reg. Societatis Humaniorum Litterarum Lundensis, 57).

PASQuali, Giorgio, “Die schriftstellerische Form des Pausanias”, Hermes, 48, 1913, pp. 161-213.

Pohlenz, Max, La liberté grecque. Nature et évolution d'un idéal de vie, París, Payot, 1956.

Porter, James, "Ideals and Ruins. Pausanias, Longinus, and the Second Sophistic", en Alcock, Cherry y Elsner 2001, pp. 63-92.

Pretzler, Maria, Pausanias. Travel Writing in Ancient Greece, London, Duckworth, 2007.

Regenbogen, Otto, "Pausanias”, RE, Suppl. 8, 1956, pp. 1008-1097.

REnAud, R., "Philopoemen”, LEC, 39, 1971, pp. 437-474.

RoBert, Carl, Pausanias als Schriftsteller. Studien und Beobachtungen, Berlín, Weidmann, 1909.

RostovtzefF, Mikhail, The Social \& Economic History of the Hellenistic World, Oxford, Clarendon Press, 1998.

SÁnchez Hernández, Juan Pablo, "Pausanias, la transformación del Oriente heleno y la crisis de la República romana (Notas a Paus. VIII, 27, 1)", Myrtia, 23, 2008, pp. 121-134.

SwaIn, Simon, Hellenism and Empire. Language, Classicism, and Power in the Greek World, AD 50-250, Oxford, Clarendon Press, 1996.

ThORNTON, John, "Pausania e la guerra acaica. Una lettura di Polibio nel II secolo d.C.", en L. Troiani e G. Zecchini (eds.), La cultura storica nei primi due secoli dell' impero romano, Roma, L'Erma di Bretschneider, 2005, pp. 199-215.

Trendelenburg, Adolf, Pausanias’ Hellenika, Berlín, Weidmann, 1914.

WACHSMUTH, Curt, "Über eine Hauptquelle für die Geschichte des achäischen Bundes”, Leipziger Studien zur classischen Philologie, 10, 1887, pp. 269-298.

Walbank, Frank, "The Problem of Greek Nationality", Phoenix, 5 (2), 1951, pp. 41-60.

Whitmarsh, Tim, The Second Sophistic, Oxford, Oxford University Press, 2005. 
